\title{
An improved iron hydroxides clogging model considering sequential intermediate pore blocking and cake filtration
}

\author{
Hexuan Zhang ${ }^{1}$, Xinqiang $\mathrm{Du}^{1}$, and xueyan $\mathrm{ye}^{1}$ \\ ${ }^{1}$ Jilin University
}

September 21, 2020

\begin{abstract}
Iron hydroxides is one of the main components of groundwater aquifer recharge clogging. Different concentrations of iron hydroxides lead to different type of clogging. Under constant flow rate, cake filtration was usually had better agreement with all the different concentration experimental results for typical single mode of clogging model. As the combined mode, the intermediate-standard and cake-intermediate models were more effective in description of the experimental data, and the combined model had more accurately fit result than the single mode model. Contributions analysis indicated that the cake filtration was the dominant clogging mechanisms for higher concentration and intermediate blocking was the dominant clogging mechanisms for lower concentration. Therefore, considering sequential intermediate blocking and cake filtration, an improved cake filtration model based on Hagen-Poseuille equation and Darcy's law was proposed. The improved model which had two model parameters, namely intermediate blocking coefficient and cake filtration coefficient are obtained by minimizing the error involved between calculated and experimental flux data. The experiment data of intermediate iron concentration was used to execute the verification model to derive two parameters which will be used to predict clogging laws of low and high iron concentration conditions, and the predicted results were fitted by experimental data. Comparing the prediction fitting error of the improved model, the result shows that it is more accurate and flexible than the original cake filtration model. Therefore, the results of the modified model can provide a basis for the subsequent use of backwash and other means to solve the blockage of colloids or complexes, thus improving the service life of the recharge facilities and saving the economic cost of the recharge.
\end{abstract}

\section{Hosted file}

Manuscript HP.docx available at https://authorea.com/users/360589/articles/482222-animproved-iron-hydroxides-clogging-model-considering-sequential-intermediate-poreblocking-and-cake-filtration 